\title{
Disconnection Syndrome and Verbal, Spatial and Tactile Amnesia following a Tumor of the Splenium of the Corpus Callosum
}

\author{
MARINA SCARPA and PAOLO SORGATO \\ Neurological Department of Modena University, Italy \\ Correspondence: M. Scarpa, Neurological Department, University of Modena, Policlinico Universitario, \\ Largo del Pozzo 7141100 Modena, Italy.
}

\begin{abstract}
A patient with a severe amnesic syndrome following a glioma of the splenium of the corpus callosum is reported. The long-term memory deficit involved anterograde as well as retrograde events dating back to 40 years and causing topographical disorientation. Short-term memory test performance was in the normal range, with the exception of tactile memory which was severely impaired.

The patient also showed disconnection symptoms, due to severing of occipito-parietal and parieto-temporal connections, while parieto-parietal connections were undamaged.
\end{abstract}

\section{Introduction}

Lesions of the corpus callosum due to tumors, infarcts or surgical section cause an inter-hemispheric disconnection syndrome. Its detection requires rather sophisticated testing techniques and indeed it escaped clinicians' attention until appropriate procedures were developed, following Myer's (1961) and Sperry's (1961) experiments. Much easier to observe is the presence of an amnesic syndrome, which has sometimes been reported in patients with lesions of the corpus callosum (Mingazzini, 1922; Risak, 1926, 1930; Scharpff, 1927; De Morsier, 1932; Magri, 1935; Halpern, 1936; Waggoner and Loewenburg, 1937; Sprofkin and Sciarra, 1952; Chimanski, 1959; Colmant and Grote, 1959; Elliott, 1969; Kretschmer, 1974), although little is known about its frequency and pathogenetic mechanism. On the basis of five personal cases and seven cases in the literature, Schlesinger (1951) stated that only lesions of the splenium were associated with memory disorders, involving both verbal and spatial memory and sometimes producing a typical Korsakoff's syndrome.

One source of information on this point comes from patients who have undergone partial or total commissurotomy either for the relief of uncontrollable seizures or for opening a route to reach subcallosal tumors. The data, however, are somewhat contradictory: all of the ten patients tested 4 to 9 years after surgery by Zaidel and Sperry (1974) showed verbal and spatial memory deficits, but the latter were less conspicuous in the two patients who $0953-4180 / 90 / 020065+11 \$ 3.50 / 0 \quad$ (C) 1990 CNS (Clinical Neuroscience) Publishers 
had the splenium preserved. On the contrary, a poor performance on verbal learning, independent of the extension of the callosal section and the involvement of the splenium, was reported by Gazzaniga (1975) in five patients, tested 1-2 years after the operation, while an improvement in postoperative performance as compared to pre-operative performance was found by Ledoux et al. (1977) in a patient who had suffered from right temporal encephalitis and had been submitted to callosotomy.

In surgical lesions of the corpus callosum in order to reach subcallosal tumors the splenium has always been spared. Nevertheless, a persistent anterograde memory deficit was reported both in Dimond et al.'s (1977) patient, and in one of the three patients studied by Jeeves et al. (1979) and in three of the six patients reported by Bentin et al. (1984).

As data from literature are scarce and contradictory, the communication of new cases is justified. The case we now report concerns a patient affected by a glioma of the splenium of the corpus callosum, who complained of a disconnection syndrome and a severe amnesic syndrome.

\section{Case Report}

A.T., aged 58, was admitted to the wards on 4 March 1988 because of a memory disorder. He was ambidextral (right hand preference on $60 \%$ of the items of Oldfield's inventory) (1971). His educational level was $8 \mathrm{yr}$ of schooling, and he had been playing an important role in a political tradeunion organization.

In May 1976 the patient had undergone an operation to remove a polar spongioblastoma situated in the right fronto-parietal white matter and was subsequently submitted to radiation therapy ( $5150 \mathrm{rad}$, on the whole). A mild left sensor-motor syndrome remained, but his mental condition was normal, and he could continue his political career. In May 1987 a CT scan examination showed no recurrences.

His present symptomatology, which had begun $1 \frac{1}{2}$ months before admission, was initially characterized by impairment of anterograde memory: his relatives noticed that he repeated the same questions many times, and forgot what happened during the day. Later, spatial memory disturbances appeared. He lost his bearings not only in the city where he had been living for many years, but also at home, where he could find the rooms only through trial and error. On admission, the neurological examination showed a mild left hemiparesis, a left hemianopia for small stimuli, with complete extinction to double stimulation, a tactile hypoaesthesia of the left hand for light stimuli with double stimulus extinction, a marked increase of two-point discrimination threshold and a conspicuous deficit of tactile localization. Statokinaesthetic sensibility was unimpaired.

On admission the patient spoke slowly and could hardly focus on the matter of discussion. He suffered from time and space disorientation, and was unconcerned about his mnesic disturbances. Language was fluent and 
correct, without paraphasias or anomias. He behaved appropriately and was respectful of social conventions; care for personal hygiene and clothing was preserved. On the first two nights in hospital, he had episodes of disorientation, excitement and confusion during which he tried to leave the neurological department.

Steroid therapy was started and improved his dullness and anxiety. $\mathrm{He}$ became co-operative and answered questions eagerly. However, his memory deficit remained unchanged. He did not remember the day he had been admitted to the ward, how long he had been in hospital (several days after admission, he thought he had just arrived) and could not find his room. Immediately after his son had left, he claimed not to have seen him for 20 days. At the end of each testing session in the doctor's office, he asked for his coat and shoes and looked for his car keys, as if had to go home. He was not able to report anything about the neuropsychological tests he had been given a few hours earlier and on one occasion he had to be reminded, at the fifteenth item, of the instructions of the test, since he had forgotten what he was expected to do. He regularly read the newspaper, but reported the news in a vague and erroneous way and was observed to read the same article repeatedly.

The amnesic syndrome extended to retrograde memory. He thought he had been operated on 2 years before and that he was still working as a town councillor, when in fact he had resigned 1 year before. He was given a questionnaire spanning the last 40 years and concerning famous political people and events, certainly familiar to him, considering his personal engagement in politics. His answers showed a severe memory deficit over the whole period examined.

While in hospital A.T. had the following examinations: EEG "slow waves in the right hemisphere and in the left occipital lobe"; Goldman campimeter "left homonymous hemianopia, sparing the macula (with middle-lightness and dimension stimuli)"; CT-scan (see Fig. 1) "infiltrating tumor involving the splenium of corpus callosum, extending along the ependyma of the trigone and the occupital horns of the lateral ventricles, and rostrally involving the cingulum surrounding the splenium, but sparing the hippocampus and the parahippocampus bilaterally and the thalamic nuclei. No obstructive hydrocephalus. Conclusion: butterfly glioma of the splenium of corpus callosum".

\section{Methods}

\section{Tests for the Disconnection Syndrome: results and discussion}

Stimuli were presented in one modality for the patient to identify them through the same or a different modality. The hemisphere receiving the information was either the same or the opposite to that providing the response. Each presentation of stimuli lasted $10 \mathrm{sec}$. In visual tests, the examiners made sure that gaze fixation was maintained. 


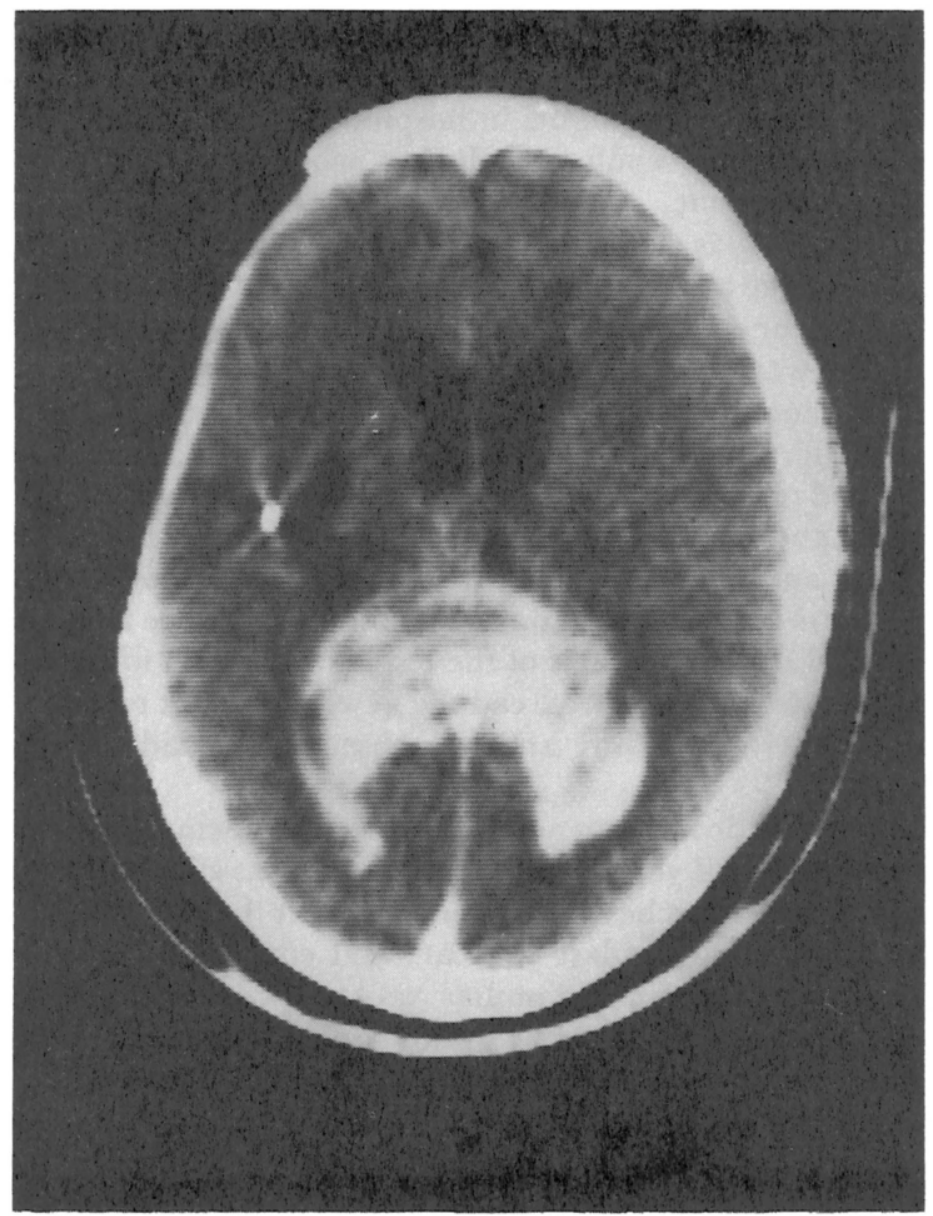

Fig. 1. Butterfly glioma of the splenium of the corpus callosum. On the right, radiological sequelae of the surgical removal of the frontoparietal polar spongioblastoma in 1976 (enhanced CT-scan axial image).

\section{Visual tests}

Tests involving visual modality were given in both fields in spite of the existence of a left hemianopia because the field defect was only apparent for small stimuli and because we wanted to verify whether operations carried out entirely within the left hemisphere were proficient. They were:

(a) Visual naming of stimuli presented in either field: 10 colors, 23 letters and 20 objects were showed for $5 \mathrm{sec}$.

(b) Visual matching (colors, letters, objects) in full view: the patient was 
required to match the stimulus presented in one hemifield with five alternatives presented in succession in full view.

(c) Visuo-visual matching in opposite fields (objects): the stimulus was presented in one hemifield and the five alternatives were presented in succession in the contralateral hemifield. The trial went on until the correct identification of the object, or until all the alternatives had been presented. The data of these three experiments are reported in Table 1 . They show low scores every time the right hemisphere is involved in processing the visual stimuli.

TABLE 1. Patient's performance on visual tests

\begin{tabular}{|c|c|c|c|c|}
\hline & & Colors & Letters & Objects \\
\hline Visual naming & $\begin{array}{l}\text { left VF } \\
\text { right VF }\end{array}$ & $\begin{array}{r}5 / 10 \\
10 / 10\end{array}$ & $\begin{array}{r}5 / 23 \\
23 / 23\end{array}$ & $\begin{array}{r}9 / 20 \\
20 / 20\end{array}$ \\
\hline $\begin{array}{l}\text { Visuo-visual matching } \\
\text { (alternatives in full view) }\end{array}$ & $\begin{array}{l}\text { left VF } \\
\text { right VF }\end{array}$ & $\begin{array}{r}5 / 10 \\
10 / 10\end{array}$ & $\begin{array}{r}5 / 10 \\
20 / 20\end{array}$ & $\begin{array}{l}11 / 20 \\
18 / 20\end{array}$ \\
\hline $\begin{array}{l}\text { Visuo-visual matching } \\
\text { (alternatives in the } \\
\text { contralateral field) }\end{array}$ & $\begin{array}{l}\text { left VF } \\
\text { right VF }\end{array}$ & - & - & $\begin{array}{r}11 / 20 \\
7 / 20\end{array}$ \\
\hline
\end{tabular}

$\mathrm{VF}=$ visual field

(d) Same-different identification of pairs of geometrical shapes, simultaneously presented in the two hemifields. The score obtained by the patient was 11/ 16.

(e) Visual-tactile matching of objects (20 stimuli):

(1) Delayed condition: the patient had to recognize the stimulus shown in one hemifield among the five alternatives presented in succession to the ipsior contralateral hand.

(2) Non delayed condition: the same as $(e) 1$, but the visual stimulus presentation was repeated before each matching trial, in order to reduce the influence of memory factors. This test was given only in the left visual field. Table 2 shows the patient's scores.

TABLE 2. Visual-tactile matching of objects

\begin{tabular}{lcccc}
\hline & \multicolumn{2}{c}{ Delayed matching } & \multicolumn{2}{c}{ Non-delayed matching } \\
& Left hand & Right hand & Left hand & Right hand \\
\hline Left VF & $6 / 20$ & $3 / 20$ & $8 / 20$ & $5 / 20$ \\
Right VF & $14 / 20$ & $17 / 20$ & - & - \\
\hline
\end{tabular}

$\mathrm{VF}=$ visual field 
(f) Tactual-visual matching of objects: the stimulus was presented in the right or the left hand, and the patient had to match it with one of the five alternatives shown in the ipsi- or contralateral hemifield. The trial continued until the identification of the stimulus or the exhaustion of the alternatives. Results are shown in Table 3:

TABLE 3. Tactual-visual matching of objects

\begin{tabular}{lcl}
\hline & Left VF & Right VF \\
\hline Left hand & $7 / 20$ & $11 / 20$ \\
Right hand & $11 / 20$ & $20 / 20$ \\
\hline
\end{tabular}

$\mathrm{VF}=$ visual field

We can summarize the data of this part of the examination as follows. When input or output processing involves the right visual area, recognition and naming are equally impaired. This happens both when the information involves the right hemisphere only, and when its analysis implies on interchange between the two hemispheres. Because of left hemianopia, results cannot be attributed to the intra-inter-hemispheric disconnection, as might be expected given the site of the lesion (Pandya, 1971). Yet, on the basis of these tests, we can maintain that the left hemisphere is working perfectly when it is the only site of perceptual operations.

There is a tactual-visual disconnection between the right parietal lobe and the left occipital lobe, as shown by the poor right visual field recognition of stimuli presented to the left hand (test $(f)$ ).

\section{Tactile tests}

The patient was blindfolded and given the following tests.

(g) Tactile naming of objects and geometrical shapes: the patient had to name 20 objects and eight wooden geometrical shapes presented to either hand.

(h) Identification with either hand of an object or a geometrical shape named by the examiner among five (objects) or eight (geometrical shapes) alternatives. The patient's scores on the two tests, shown in Table 4, indicate that the performance was perfect with the right hand and markedly impaired with the left hand.

TABLE 4. Tactile naming and identification on oral command of objects and geometrical shapes

\begin{tabular}{lcccc}
\hline & \multicolumn{2}{c}{ Naming } & \multicolumn{2}{c}{ Identification } \\
& Objects & Shapes & Objects & Shapes \\
\hline Left hand & $7 / 20$ & $4 / 8$ & $10 / 20$ & $2 / 8$ \\
Right hand & $20 / 20$ & $8 / 8$ & $20 / 20$ & $8 / 8$ \\
\hline
\end{tabular}


(i) Tactual-tactile matching of objects: (1) Delayed matching: the stimulus was presented to one hand of $5 \mathrm{sec}$ and then five alternatives were presented to the same or contralateral hand for the patient to recognize the stimulus. Twenty objects were used. (2) Non-delayed matching: the procedure was the same as in the preceding test, but stimulus presentation was repeated before each matching trial, so as to reduce to a minimum the influence of memory. The patient's scores on these two tests are reported in Table 5. In the delayed condition, stimuli palpated with the right hand were matched much better than those palpated with the left hand. However, the latter performance remarkably improved, when immediate recognition was requested.

(l) Same-different discrimination of geometrical shapes simultaneously given to the two hands. The score obtained by the patient was 10/12.

The most likely interpretation of tactile test findings is in terms of hemisphere disconnection, even if there was a sensory deficit in the left hand. That this deficit was not responsible for the performance deterioration is suggested by the high score $(10 / 12)$ obtained in the same-different discrimination of geometrical shapes simultaneously presented to the two hands (test $(l))$ and by the nearly equal performance of the left $(17 / 20)$ and right hand $(15 / 20)$ in recognizing an object first palpated with the left hand in the non-delayed condition (test $(l 2)$ ). It would appear that the two parietal lobes maintained the capability to communicate with each other, which is not surprising as the tumor did not encroach upon the anterior part of the posterior half of corpus callosum, where parieto-parietal connections run (Pandya, 1969, 1971).

The finding of a conspicuous worsening of the performance when a delay was introduced between stimulus presentation and identification (compare test ( $l 1)$ with test (l2) suggests a deficit of tactile memory analogous to that reported by Bentin and Sahar (1984) in commissurotomized patients.

The difference between the right and the left hand performance on tactual naming indicates at least a partial disconnection between the right parietal and left temporal areas. It can be inferred that the connections between these areas run a transcallosal pathway posterior to the one followed by parieto-parietal connections, which are intact (Barbizet, 1974).

The data can be summarized by stating that a lesion confined to the splenium of corpus callosum, such as the one found in our patient, involves parieto-temporal and parieto-occipital connections and leaves parietoparietal connections intact.

TABLE 5. Tactual-tactile matching of objects

\begin{tabular}{lcccc}
\hline & \multicolumn{2}{c}{ Delayed matching } & \multicolumn{2}{c}{ Non-delayed matching } \\
& Left hand & Right hand & Left hand & Right hand \\
\hline Left hand & $10 / 20$ & $7 / 20$ & $15 / 20$ & $15 / 20$ \\
Right hand & $17 / 20$ & $20 / 20$ & - & - \\
\hline
\end{tabular}




\section{Intelligence and Memory Testing: results and discussion}

WAIS: Verbal IQ $=123$; Performance $\mathrm{IQ}=83$; Full Scale $\mathrm{IQ}=107$.

Verbal Memory (Cut off scores in De Renzi 1977).

Digits forwards: 5 (normal score: $7+2$ ), Story recall (no. of elements recalled): 6.94 (cut-off score: $15 \cdot 76$ ).

Learning a 10-word list (mean no. of words per trial): 6.61 (cut-off score: $6 \cdot 58)$.

Learning a 10 paired-associate list (cumulative score over three trials(: 6.33 (cut-off score: 8.73).

Spatial Memory. Cube span (Corsi's block test): 4 (mean normal score: 5.92; cut-off score: 4). Learning a spatial, supraspan sequence $(\operatorname{span}+2)$ on Corsi's block test: the patient reached the criterion after 16 essays (normal score: $11 \cdot 94+7 \cdot 75)$.

Memory for Famous People (photographs): 30/40 (within normal range).

\section{Discussion}

Our patient's most striking disturbance was a severe global amnesic syndrome, closely resembling Korsakoff's syndrome and involving anterograde as well as retrograde memory. Both verbal and spatial information could not be retrieved from the long-term store, while there was no deficit in face recognition. Testing confirmed the impairment of long-term verbal memory, but surprisingly not that of spatial memory, which was, markedly disrupted in every day behavior. This finding questions the relevance of Corsi's supraspan test for assessment of topographical amnesia. It is worth stressing that the disorder of topographic memory cannot be attributed to the right parietal lesion caused by the previous tumor, since it was absent following the operation and only appeared one and a half months before admission.

Our patient's memory defect contradicts Zaidel and Sperry's (1974) hypothesis that past memories are stored in the left hemisphere and that the splenium has only the function of acquiring new memories. In fact, A.T. showed a definite loss of both anterograde and retrograde memory in spite of an anatomically and functionally intact left hemisphere. Therefore, in our opinion, the role of the splenial connections cannot be limited to the acquisition and storing of engrams, but must also be operative during their retrieval.

Short-term memory deficit are frequently reported in patients submitted to callosotomy, but this often refers inappropriately to memory for recent events, while it should indicate information not exceeding the patient's span and rehearsed within a few seconds. Only Zaidel and Sperry (1974) appear to define short-term memory correctly in the literature. They found a definite deficit in verbal and spatial short-term memory tests. This finding, however is not confirmed by our patient, whose verbal and spatial short term memory was within the normal range.

The greater severity of the amnesic syndrome shown by the present 
patient as well as by other patients with tumors of the splenium (Schlesinger, 1951) when compared to patients submitted to complete callosotomy, raises the question of whether the deficit is entirely attributable to the interruption of splenial pathways or also to damage to adjacent brain structures. For example, Signoret (1985) ascribed the amnesic syndrome to bilateral damage to the posterior cingulate gyri. It is doubtful, however, whether the cingulum actively participates in memory functions. In Whitty and Lewin's (1960) study, eight patients out of 14 submitted to bilateral cingulectomy for psychiatric diseases, showed a transient confabulatory syndrome. Fedio and Ommaya $(1970,1972)$ reported a deficit of verbal and spatial memory during electrical stimulation of the left and right cingulum, respectively, but since no difference in their patients' memory was found before and after bilateral cingulectomy, they suggested that the amnesic effect of the cingulum stimulation was due to its spreading to the temporal limbic structures. Also Angelini (1980) and Corkin (1980) failed to find any difference in the performance on memory tests before and after cingulectomy in the 56 patients they examined.

The importance of lesions involving the fornix in producing memory deficits is recognised. Heilman and Sypert (1977) and Tucker et al. (1988) suggest the fornix may produce amnesia through hippocampal disconnection, while other authors found no memory deficit following surgical lesion of the fornix (Cains and Mosberg, 1951; Garcia Bengochea et al., 1954; Woolsey and Nelson, 1975).

Valenstein et al. (1987) have recently suggested that the amnesic syndrome shown by many cases of tumors of the corpus callosum or fornix should be attributed to damage to the retrosplenial cortex, which seems to be intimately connected with the anterior thalamic nuclei and the medial temporal structures. According to the authors, amnesia should "result from lesions in either retrosplenial cortex or the cingulate bundle (or both)". As our patient had quite a large tumor of the splenium, his amnesia could also be explained in terms of a lesion of the retrosplenial region. The reverse, however, could be suggested for the patient reported by Valenstein et al. (1987), who was affected by a haemorrhage involving both the retrosplenial cortex and the splenium itself.

In conclusion, our study, adds data to the controversy on the role played by the splenium of the corpus callosum in acquiring and recalling mnestic engrams, and underscores its relevance in connecting occipito-parietal and temporo-parietal lobes.

\section{References}

Angelini, L., Mazzucchi, A., Picciotto, F., Nardocci, N. and Broggi, G. (1980). Focal lesion of the right cingulum: a case report in a child. Journal of Neurology, Neurosurgery and Psychiatry, 43, 355-357.

Barbizet, J., Degos, J. D., Duizabo, P. and Chartier, B. (1974). Syndrome de deconnexion interhemispherique d'origine ischemique. Revue Neurologique, 130, 127-141.

Bentin, S., Sahar, A. and Moscovitch. M. (1984). Intermanual information transfer in patients with lesions in the trunk of the corpus callosum. Neuropsychologia, 22, 601-612. 
Cairns, H. and Mosberg, W. H. (1951). Colloid cyst of the third ventricle. Surgery, Gynecology and Obstetrics, 92, 545-570.

Chimanski, K. V. (1959). Les difficultés et les erreurs dans le diagnostique des tumeurs du corps calleux. Zeitschrift Nevropathologie und Psychiatrie, 59, 1057-1061.

Colmant, H. J. and Grote, W. (1959). Tumoren der Balkenregion, Zur Klinik und Pathologie der Mittelliniengliome. Schweizer Archiv für Neurologie und Psychiatrie, 84, 47--96.

Corkin, S. (1980). A prospective study of cingulotomy. In "The Psychosurgery Debate". (Ed. E. Valenstein) Freeman Co., San Francisco, pp. 164-204.

Degos, J. D., Gray, F., Louarn, F., Ansquer, J. C., Poirier, G. and Barbizet, J. (1987). Posterior callosal infarction. Clinicalpathological correlations. Brain, 110, 1155-1171.

De Morsier, G. (1932). Contribution a l'étude anatomoclinique de la fonction amnesique. Un cas de syndrome amnesique avec gliome du splenium du corps calleux. Schweizer Archiv für Neurologie und Psychiatrie, 28, 283-292.

De Renzi. E. (1977). Le amnesie. In "Neuropsicologia Clinica". (Ed. F. Angeli), pp. 199-246.

Dimond, S. J., Scannel, R. E., Browers, E. Y. M. and Weeks, R. (1977). Function of the centre section (trunk) of the corpus callosum in man. Brain, 100, 543-562.

Elliott, F. A. (1969). The corpus callosum, cingulate gyrus, septum pellucidum, septal area and fornix. In "Handbook of Neurology". Vol. 2. (Eds. P. J. Vinken and G. W. Bruyn). North Holland Publishing Co., Amsterdam, pp. 758-775.

Fedio, P. and Ommaya, A. K. (1970). Bilateral cingulum lesions and stimulation in man with lateralized impairment in short-term verbal memory. Experimental Neurology, 29, 84-91.

Fedio, P. and Ommaya, A. K. (1972). The contribution of cingulum and hippocampal structures of memory mechanisms in man. Confinia Neurologica, 34, 398-411.

Garcia Bengochea, F., De La Torre, O., Vieta, R. and Fernandez, C. (1954). The section of the fornix in the surgical treatment of certain epilepsies: a preliminary report. Transactions of the American Neurological Association, 79, 176-178.

Gazzaniga, M. S. (1975). Review of the split brain. Journal of Neurology, 209, 75-79.

Halpern, L. (1936). Beiträge zur Neurologie des Stirnhirns und des Balkens. I. Über eine Stirnhirnbalkensyndrome bei Geschwuelsten. Schweizer Archiv für Neurologie und Psychiatrie, 37, 68-76.

Heilman, K. M. and Sypert, G. W. (1977). Korsakoff's syndrome resulting from bilateral fornix lesions. Neurology, 27, 490-493.

Jeeves, M. A., Simpson, D. A. and Geffen, G. (1979). Functional consequences of the transcallosal removal of intraventricular tumors. Fournal of Neurology, Neurosurgery and Psychiatry, 42, 134-142.

Kretschmer, H. (1974). Callosal tumours. In "Handbook of Neurology" Vol. 17. (Eds. P. J. Vinken and G. W. Bruyn). North Holland Publishing Co., Amsterdam, pp. 490-554.

Ledoux, J. E., Risse, G. L., Springer, S. P., Wilson, D. H. and Gazzaniga, M. S. (1977). Cognition and commissurotomy. Brain, 100, 87-104.

Magri, F. (1935). Esame istologico di un sarcoma del corpo calloso. Rassegna di Studi Psichiatrici, 24, 957-975.

Mingazzini, G. (1922). "Der Balken, Eine anatomische, physiologische und klinische Studie". Springer, Berlin.

Myers, R. E. (1961). Corpus callosum and visual gnosis. In "Brain Mechanisms and Learning". (Ed. A. Fessard). Blackwell, Oxford.

Oldfield, R. C. (1971). The assessment and analysis of handedness: the Edinburgh Inventory. Neuropsychologia, 9, 97-113.

Pandya, D. N., Karol, E. A. and Heilbronn, D. (1971). The topographical distribution of interhemispheric projections in the corpus callosum of the rhesus monkey. Brain Research, 32, 31-43.

Risak, E. (1926). Über die Balkensymptome. Wiener klinischer Wochenschrift, 45, 1340-1374.

Risak, E. (1930). Zur Diagnostik der Balkengeschwuelste. Zeitschrift für gesamte Neurologie und Psychiatrie, 130, 346-356.

Scharpff, W. (1927). Über das Auftreten von polymorphkerniger Leucocytose in Liquor cerebrospinalis bei Hirntumor. Deutsche Zentralblatt Nervenheilkunde, 96, 112-123.

Schlesinger, B. (1951). Gliomas involving the splenium of the corpus callosum. Neurology, 1, $419-432$. 
Signoret, J. L. (1985). Memory and amnesias. In "Principles of Behavioral Neurology". (Ed. M. M. Mesulam). Davis FA Co., Philadelphia, pp.. 169-192.

Sperry, R. W. (1961). Cerebral organization and behavior. Science, 133, 1749-1757.

Sprofkin, B. E. and Sciarra, D. (1952). Korsakoff's psychosis associated with cerebral tumors. Neurology, 2, 427-434.

Tucker, D. M., Roeltgen, D. P., Tully, R., Hartmann, J. and Boxell, C. (1988). Memory dysfunction following unilateral section of the fornix: a hippocampal disconnection syndrome. Cortex, 24, 465-472.

Valenstein, E., Bowers, D., Verfallie, M., Heilman, K. M., Day, A. and Watson, R. T. (1987). Retrosplenial amnesia. Brain, 110, 1631-1646.

Waggoner, R. W. and Loewenburg, K. (1937). A clinicopathologic study of astrocytomas. Archives of Neurology and Psychiatry, 38, 1208-1223.

Whitty, C. W. and Lewin, W. (1960). A Korsakoff syndrome in the postcingulectomy confusional state. Brain, 83, 648-653.

Woolsey, R. M. and Nelson, J. S. (1975). Asymptomatic destruction of the fornix in man. Archives of Neurology, 32, 566-568.

Zaidel, D. and Sperry, R. W. (1974). Memory impairment after commissurotomy in man. Brain, 97, 263-272. 


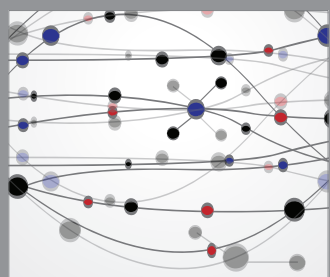

The Scientific World Journal
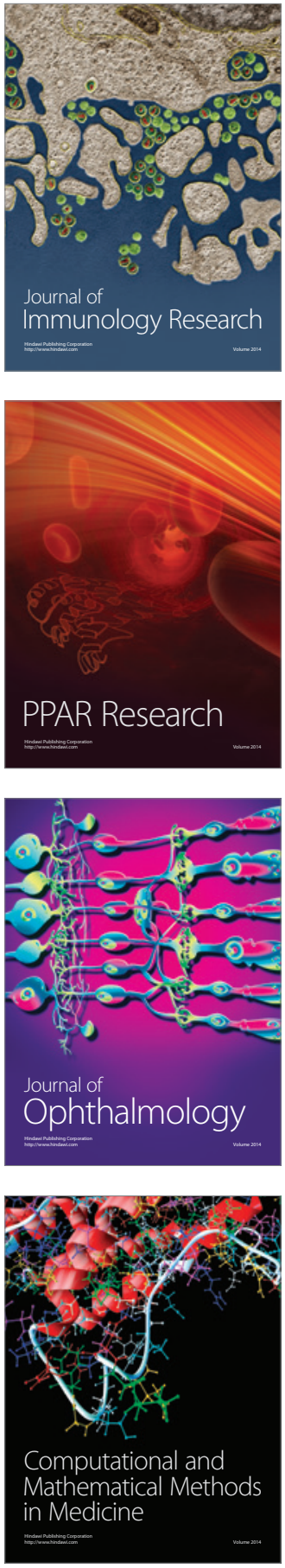

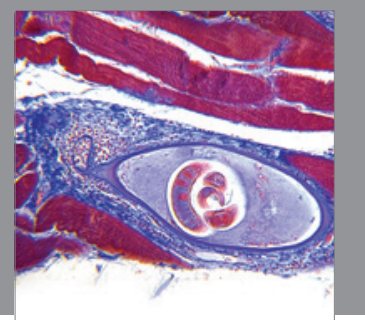

Gastroenterology

Research and Practice
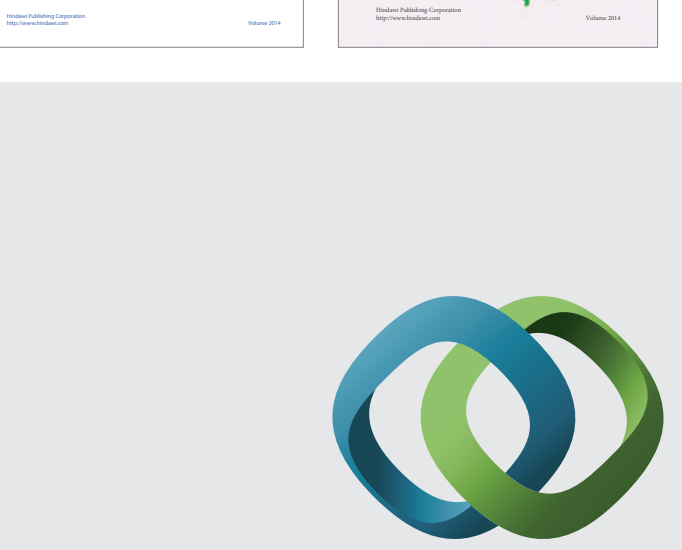

\section{Hindawi}

Submit your manuscripts at

http://www.hindawi.com
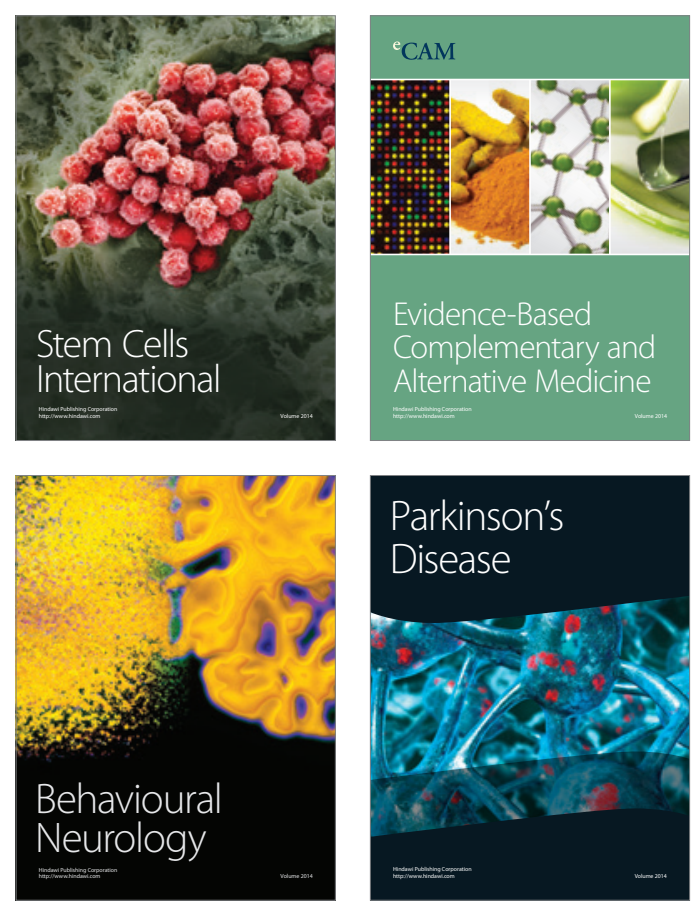

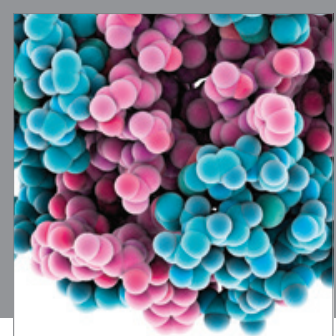

Journal of
Diabetes Research

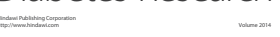

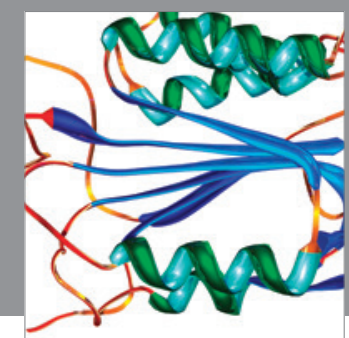

Disease Markers
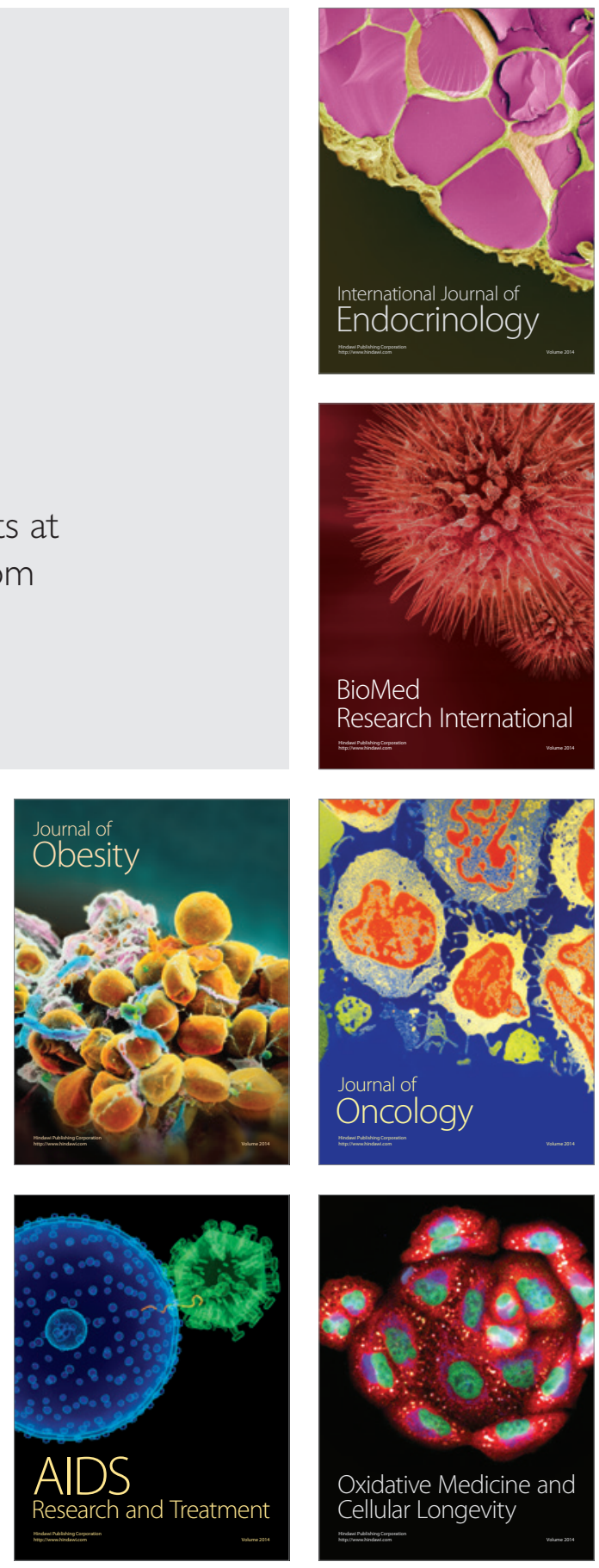